\title{
Endogenous Endothelin-1 Regulates Hypoxia-Induced Atrial Natriuretic Peptide Secretion by Activating the MAPK/ERK and PI3K/Akt Signaling Pathways in Isolated Beating Rabbit Atria
}

\author{
Chaochao Bian 1*, Dazhi Ding2*, Honghua Jin², Liping Liu1, Lan Hong1, Bairi Cui ${ }^{1,2 \#,}$ \\ Xun Cui 1,3,4 \\ ${ }^{1}$ Department of Physiology, School of Medicine, Yanbian University, Yanji, China \\ ${ }^{2}$ Institue of Clinical Medicine, Yanbian University, Yanji, China \\ ${ }^{3}$ Key Laboratory of Organism Functional Factors of the Changbai Mountain, Ministry of Education, Yanbian \\ University, Yanji, China \\ ${ }^{4}$ Cellular Function Research Center, Yanbian University, Yanji, China \\ Email: "cui_bairi@163.com, ${ }^{\dagger}$ cuixun@ybu.edu.cn
}

Received 17 November 2015; accepted 8 January 2016; published 11 January 2016

Copyright (C) 2016 by authors and Scientific Research Publishing Inc.

This work is licensed under the Creative Commons Attribution International License (CC BY). http://creativecommons.org/licenses/by/4.0/

(c) (i) Open Access

\section{Abstract}

The present study investigated a possible mechanism for endogenous endothelin-1 (ET-1) regulation of atrial natriuretic peptide (ANP) secretion in isolated perfused acute hypoxic rabbit atria. Acute hypoxia significantly enhanced the release of ET-1 and the expression of the ET receptor (ETR) type $A$ and $B\left(E R_{A}\right.$ and $\left.E R_{B}\right)$ in atrial tissues, with a concomitant increase in ANP secretion. The ETR $_{A}$ or ETR E $_{B}$ antagonist, BQ123 $(0.3 \mu \mathrm{mol} / \mathrm{L})$ or BQ788 $(0.3 \mu \mathrm{mol} / \mathrm{L})$, respectively attenuated hypoxia-induced ANP secretion. Both antagonists significantly attenuated the levels of hypoxiainduced atrial phosphorylated (p)-extracellular signal-regulated kinase (ERK) and p-protein kinase B (Akt). The ERK and Akt inhibitors, PD098059 (30 $\mathrm{mol} / \mathrm{L})$ and LY294002 (30 $\mu \mathrm{mol} / \mathrm{L})$, respectively mimicked the effect of the ETR antagonists. These results demonstrated that acute hypoxia-mediated atrial ET-1 regulated ANP secretion through ETR and the subsequent mitogenactivated protein kinase (MAPK)/ERK and ETR-phosphatidylinositol-3-kinase (PI3K)/Akt signaling pathways. These pathways may mediate atrial endocrine functions under hypoxic conditions.

\footnotetext{
These authors contributed equally to this work.

\#Co-corresponding author.

${ }^{\dagger}$ Corresponding author.
}

How to cite this paper: Bian, C.C., et al. (2016) Endogenous Endothelin-1 Regulates Hypoxia-Induced Atrial Natriuretic Peptide Secretion by Activating the MAPK/ERK and PI3K/Akt Signaling Pathways in Isolated Beating Rabbit Atria. Journal of Biosciences and Medicines, 4, 45-53. http://dx.doi.org/10.4236/jbm.2016.41006 
Keywords

Hypoxia, Endothelin-1, ET Receptor, Atrial Natriuretic Peptide, Signaling Pathway

\section{Introduction}

Hypoxia is a common pathological condition in most cardiac diseases such as myocardial hypertrophy and infarction [1] [2]. Numerous studies have clearly shown that hypoxia stimulates the secretion of atrial natriuretic peptide (ANP), resulting in cellular adaptation to hypoxia and protection of the ischemic heart [3]-[5]. However, the mechanism by which hypoxia induces ANP secretion is not well known.

Endothelin (ET)-1 is the predominant ET isopeptide in the heart [6]. ET-1 is an important regulator of cardiac function, and its cardiac and plasma levels are elevated in myocardial infarction, hypertension, and heart failure [7]-[9]. ET-1 has been shown to the most potent stimulus for ANP secretion [10]. We have previously reported that ET-1 significantly promotes ANP secretion via the endothelin receptor type B (ETRB) mitogen-activated protein kinase (MAPK)/extracellular signal-regulated kinase (ERK) signaling pathway under normoxic conditions in isolated perfused beating rabbit atria [11]. Moreover, other studies have demonstrated that hypoxia significantly increases the production of ET-1 [2] [12] and that hypoxia-induced ET-1 is involved in the regulation of ANP secretion [10] [13]. However, results for the role of ETRs, ETRA, and ETRB, in the regulation of hypoxia-induced ANP secretion are conflicting. Skvorak et al. [14] have shown that a period of anoxia in the isolated perfused rat atria causes a dramatic increase in ANP secretion, which is almost entirely blocked by the ETRA antagonist BQ123. However, Zhang et al. [13] have reported that the nonselective ETR antagonist bosentan, but not BQ123, significantly attenuates hypoxia-induced ANP release. Overall, the mechanism by which endogenous ET-1 regulates hypoxia-induced ANP secretion remains to be defined.

The purpose of the present study was to investigate the mechanism by which hypoxia-induced endogenous ET-1 regulates ANP secretion in isolated perfused beating rabbit atria. We investigated the role of ETR and their downstream signaling pathways, MAPK/ERK and phosphatidylinositol-3-kinase (PI3K)/protein kinase B (Akt), on the regulation of hypoxia-mediated ANP secretion.

\section{Materials and Methods}

\subsection{Preparation of Perfused Beating Rabbit Atria}

\subsubsection{Isolated Perfused Beating Rabbit Atrial Model Preparation}

The atria (mean wet weight of $167.00 \pm 4.2 \mathrm{mg}$ ) of adult New Zealand white rabbits of either sex were used. The isolated perfused beating left atrial model was prepared as previously described [15]. The beating atrium was perfused with HEPES buffer solution ([in mmol/L]: $118 \mathrm{NaCl}$, $4.7 \mathrm{KCl}, 2.5 \mathrm{CaCl}_{2}, 1.2 \mathrm{MgCl}_{2}, 25 \mathrm{NaHCO}_{3}, 10$ glucose, 10 HEPES, $0.1 \%$ bovine serum albumin; $\mathrm{pH} 7.4)$. The peristaltic pump $(1 \mathrm{~mL} / \mathrm{min})$ allowed atrial pacing for measurements of the changes in atrial volume (stroke volume) and the secretion of ET-1 and ANP. Transmural electrical field stimulation with a luminal electrode was operated at $1.5 \mathrm{~Hz}(0.3 \mathrm{~ms}, 30-40 \mathrm{~V})$. The perfused atrium was supplied with sufficient oxygen during the entire process.

\subsubsection{Acute Hypoxic Atrial Model Preparation}

The acute hypoxic atrial model was prepared by replacing $\mathrm{O}_{2}$ gas with $\mathrm{N}_{2}$ gas and normal HEPES buffer with $\mathrm{N}_{2}$ saturated HEPES buffer. The criteria for successful hypoxic atrial modeling included markedly increased secretion of ANP and significant inhibitory atrial dynamics.

\subsection{Experimental Grouping}

To investigated effect of hypoxia on atrial ANP secretion, ET-1 release and ETRs levels, 25 of rabbits were randomly divided in to atrial ANP secretion and dynamics ((a) and (b), $n=5)$, ET-1 release ((c), n = 5), ETR $((d), n=5), E_{B}((e), n=5)$ and control groups ((c), (d) and (e), $\left.n=5\right)$ (Figure 1). For the control group, vehicle was introduced and the values obtained during the periods corresponding to the control and experimental observation were compared. 
(a)

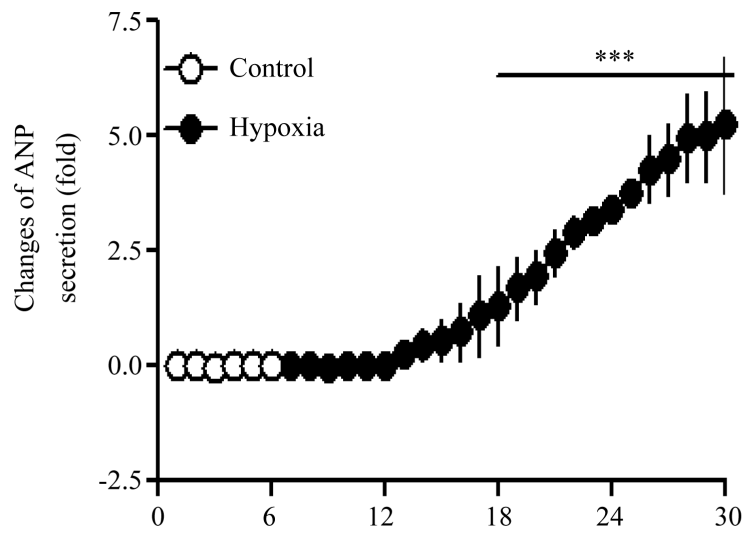

(b)

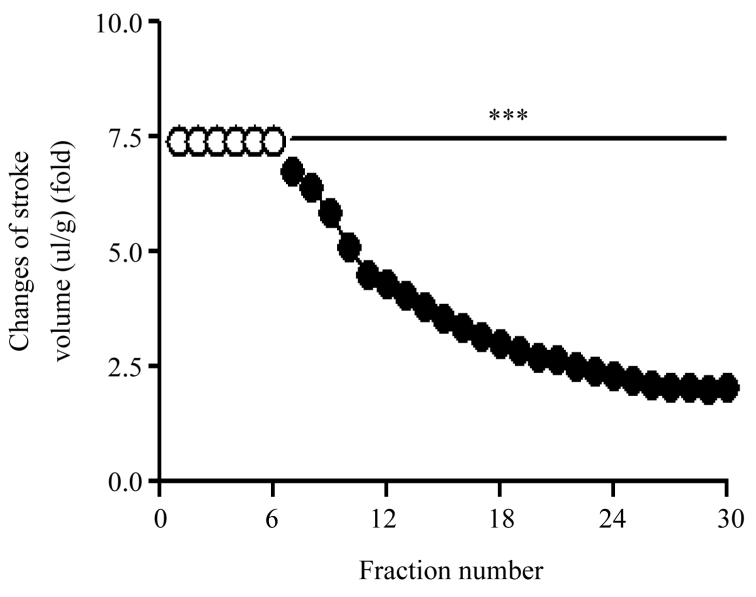

(c)

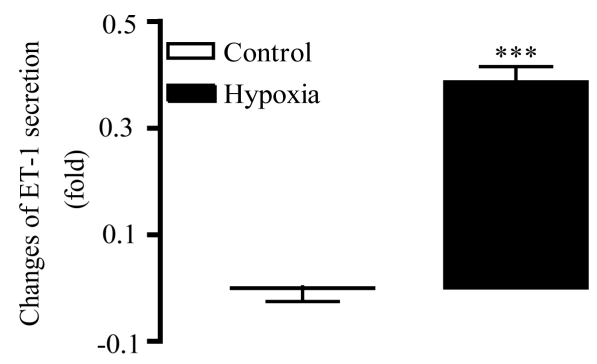

(d)
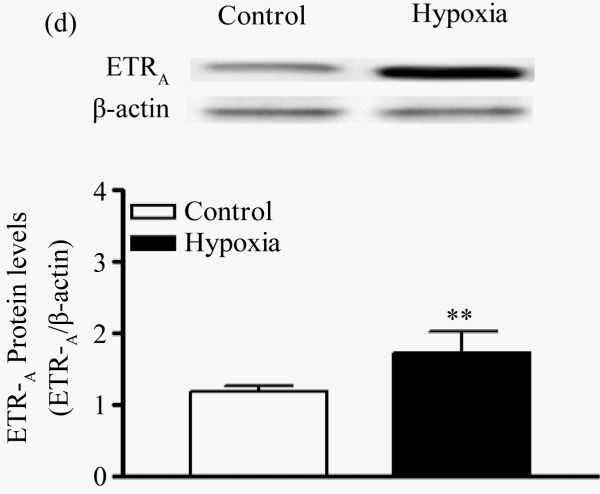

(e)
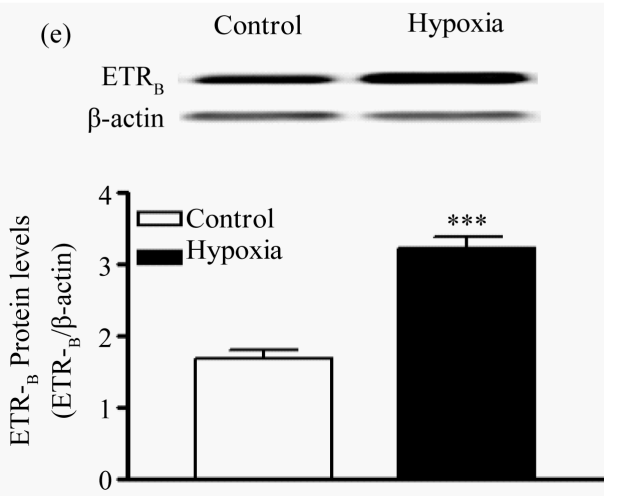

Figure 1. Effect of acute hypoxia on atrial ANP secretion (a), dynamics (b), ET-1 release, (c) and ET receptor type A $\left(E R_{A}\right)$ and type $B\left(E_{B}\right)((d)$ and $(e))$ in isolated perfused beating rabbit atria. Data are expressed as the mean \pm SE $(n=$ 5). ${ }^{* *} \mathrm{P}<0.01,{ }^{* * *} \mathrm{P}<0.001$ vs. control.

For roles of ET receptors antagonists on hypoxia-induced atrial ANP secretion experiments, 24 of rabbits were randomly divided in to hypoxia ((Aa), (Ba) and (Ca), n=6), BQ123 ((Aa), n=6), BQ788 ((Ba), n=6) and combined treatment of BQ123 plus BQ788 groups $((\mathrm{Ca}), n=6)$ (Figure 2).

Another experiments for roles of ERK and Akt antagonists on hypoxia-induced atrial ANP secretion, 12 of rabbits were randomly divided in to hypoxia ((Aa) and (Ba), $n=6)$, PD98059 ((Aa), n = 6), LY294002 groups ((Ba), $\mathrm{n}=6$ ) (Figure 3).

Finally, to determined roles of ET receptors antagonists on hypoxia-induced atrial ERK and Akt levels, 25 of rabbits were randomly divided in to control ((a) and (b) = 5), hypoxia ((a) and (b), n= 5), BQ123 ((a) and (b), n = 5), BQ788 ((a) and (b), $n=5)$ and combined treatment of BQ123 plus BQ788 groups ((a) and (b), $n=5)$ (Figure 4).

\subsection{Experimental Protocols}

Each atrium was perfused for 60 min to stabilize the parameters of ET-1, ANP secretion, and atrial dynamics. 

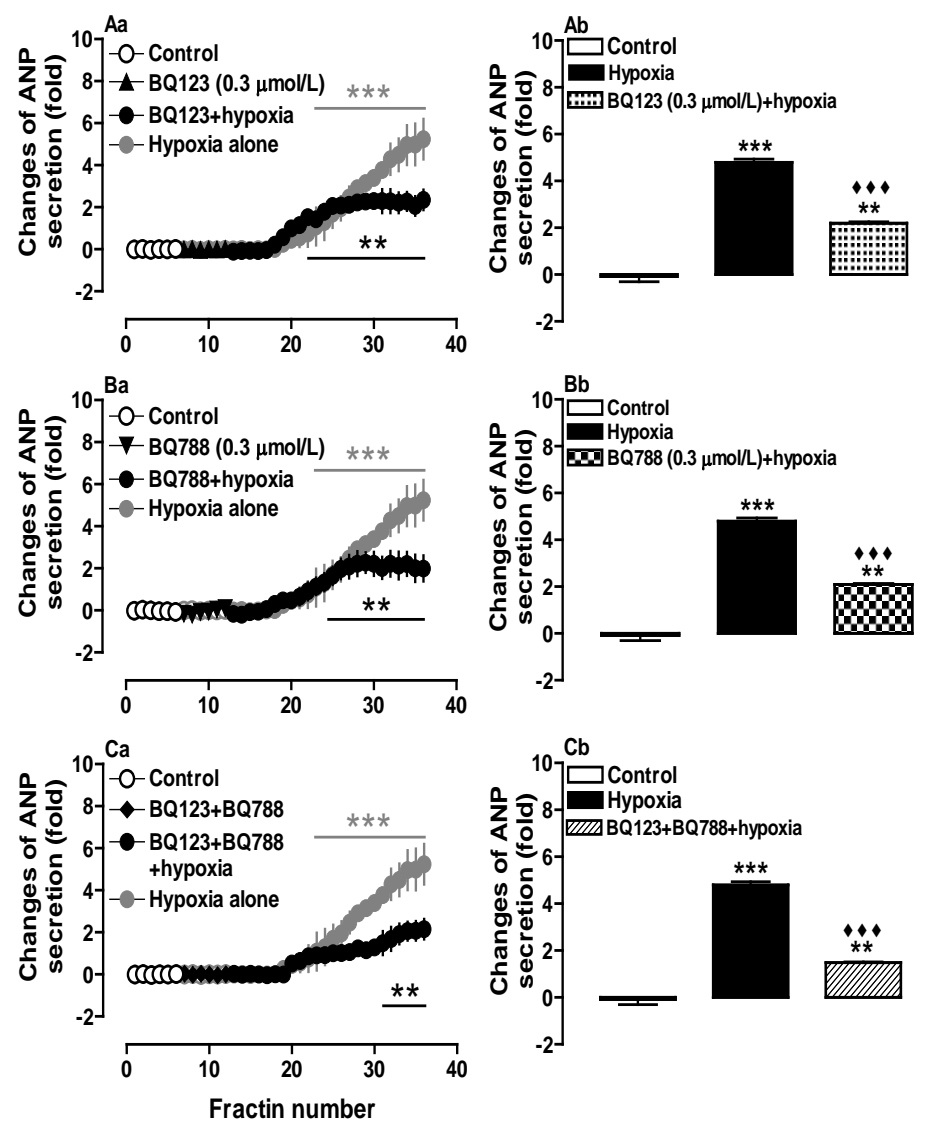

Figure 2. Effects of BQ123 $(0.3 \mu \mathrm{mol} / \mathrm{L}, \mathrm{Aa}), \mathrm{BQ788}(0.3 \mu \mathrm{mol} / \mathrm{L}, \mathrm{Ba})$ and
$\mathrm{BQ} 123$ plus BQ788 $(\mathrm{Ca})$ on the hypoxia-induced secretion of ANP in beating
rabbit atria. Data of Ab-Cb were derived from Aa-Ca. Data are expressed as
the mean $\pm \mathrm{SE}(\mathrm{n}=6) .{ }^{* *} \mathrm{P}<0.01,{ }^{* * *} \mathrm{P}<0.001 \mathrm{vs}$ control; ${ }^{* * *} \mathrm{P}<0.001 \mathrm{vs}$.
hypoxia.

The control cycle (12 min as an experimental cycle) was followed by the infusion of hypoxic buffer for four cycles. The changes in atrial dynamics were recorded by the RM-6240 system. ET-1 and ANP levels were determined by radioimmunoassay in the perfusate, which was collected at 2 min intervals $\left(a t 4^{\circ} \mathrm{C}\right)$. Immediately after perfusion, the atrial tissues were collected, frozen in liquid nitrogen, and stored at $-80^{\circ} \mathrm{C}$ for future use in western immunoblotting.

A separate series of experiments was performed to investigate the mechanism by which endogenous ET-1 regulates acute hypoxia-induced ANP secretion. After the control period, the treatment cycle was followed by four cycles of infusion of the treatment agent plus hypoxia. The treatment agents were as follows: 1$)$ the $\mathrm{ETR}_{\mathrm{A}}$ antagonist BQ123 $(0.3 \mu \mathrm{mol} / \mathrm{L} ; \mathrm{n}=6) ; 2)$ the $\mathrm{ETR}_{\mathrm{B}}$ antagonist BQ788 $\left.(0.3 \mu \mathrm{mol} / \mathrm{L} ; \mathrm{n}=6) ; 3\right)$ the MAPK/ERK inhibitor PD098059 (30 $\mu \mathrm{mol} / \mathrm{L} ; \mathrm{n}=6)$; 4) the PI3K/Akt inhibitor LY294002 $(30 \mu \mathrm{mol} / \mathrm{L} ; \mathrm{n}=6)$.

\subsection{Radioimmunoassay of ANP Concentrations}

The levels of ET-1 and immunoreactive ANP in the perfusate were measured by a specific radioimmunoassay as described previously [16]. The amounts of secreted ET-1 and ANP were expressed as ng/min/g of wet atrial tissue.

\subsection{Western Immunoblot Analysis}

Protein from left atrial tissues was tested by western blotting. The atrial tissues were homogenated in radio immunoprecipitation assay lysis buffer (Solarbio institute of Biotechnology, Shanghai, China), and protein 

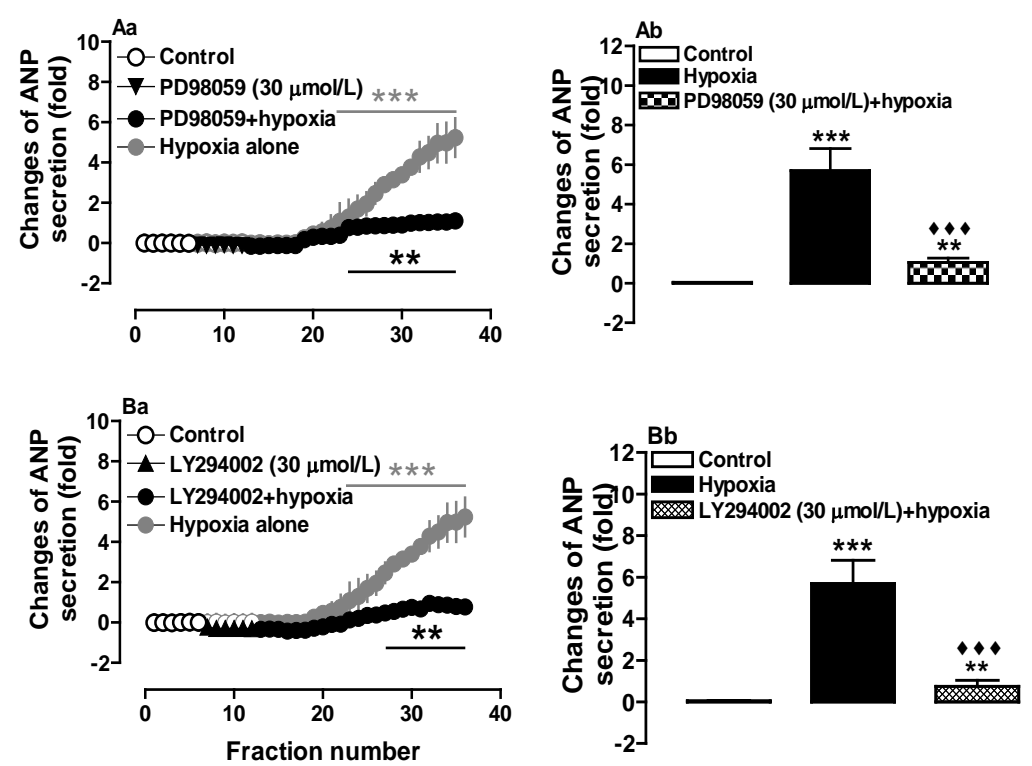

Figure 3. Effects of LY294002 (30.0 $\mu \mathrm{mol} / \mathrm{L}, \mathrm{Aa})$ and PD98059 (30.0 $\mu \mathrm{mol} / \mathrm{L}, \mathrm{Ba})$ on the hypoxia-induced secretion of ANP. Data of Ab, Bb were derived from Aa, Ba. Data are expressed as the mean \pm SE $(n=6) .{ }^{* *} \mathrm{P}<0.01,{ }^{* * *} \mathrm{P}<0.001$ vs. control; ${ }^{* * *} \mathrm{P}$ $<0.001$ vs. hypoxia.

concentrations were determined using the Bradford Protein Assay Kit. Solubilized protein was denatured in Lane Maker Loading buffer, assayed by $10 \%$ or $8 \%$ sodium dodecyl sulfate polyacrylamide gel electrophoresis and transferred to polyvinylidene difluoride filter membranes (Beyotime institute of Biotechnology, China). Membranes were blocked with 5\% nonfat dry milk in phosphate buffer solution (PBST) at room temperature. After 2 hours, the membrane were incubated with goat polyclonal anti-ET $\mathrm{A}_{\mathrm{A}}$ (1:100; Santa Cruz Biotechnology, Hong Kong), rabbit polyclonal anti-ET $\mathrm{B}_{\mathrm{B}}$ (1:1000; Abcam, Hong Kong), rabbit polyclonal p-Akt (1:1000; Abcam Hong Kong) or p-ERK (1:1000; Cell Signaling Technology, Shanghai, China), all with rabbit polyclonal $\beta$-actin (1:1000; ComWin Biotech, Beijing, China) at $4^{\circ} \mathrm{C}$, overnight. Membranes were incubated with the secondary antibodies (1:2000) for $2 \mathrm{~h}$ at room temperature. After extensive washing with PBST, bands were visualized with the ECL Plus Western blotting detection system (ECL Western Blot Kit ComWin Biotech, Beijing, China) and then quantified using Image $\mathrm{J}$ software.

\subsection{Statistical Analysis}

All data are presented as mean \pm SEM and were analyzed by the one-way analysis of variance followed by the Dunnett's multiple comparison test. An unpaired t-test was also applied. Statistical significance was defined as $\mathrm{P}$ $<0.05$.

\section{Results}

\subsection{Acute Hypoxia Potently Promoted Atrial ANP, ET-1 Secretion and the Expression of ETRs}

Acute hypoxia significantly ( $\mathrm{P}<0.001$ vs. control; $\mathrm{n}=6$ ) increased and decreased ANP secretion and atrial stroke volume, respectively in isolated perfused beating rabbit atria (Figure 1(a) and Figure 1(b)). These results suggested that the acute hypoxia model in the isolated perfused beating rabbit atria was successful.

Acute hypoxia markedly ( $\mathrm{P}<0.001$ vs. control; $\mathrm{n}=6$ ) promoted the release of atrial ET-1 (Figure $1(\mathrm{c})$ ). Furthermore, western blotting analysis revealed that the expression of $\mathrm{ETR}_{\mathrm{A}}$ and $\mathrm{ETR}_{\mathrm{B}}$ was markedly $(\mathrm{P}<0.01$ and $\mathrm{P}<0.001$, respectively vs. control; $\mathrm{n}=6$ ) increased in perfused beating rabbit atrial tissues under acute hypoxic conditions (Figure 1(d) and Figure 1(e)). These results indicated that acute hypoxia promoted the release of atrial ET-1 and upregulated the expression of both ETR types. 
(a)
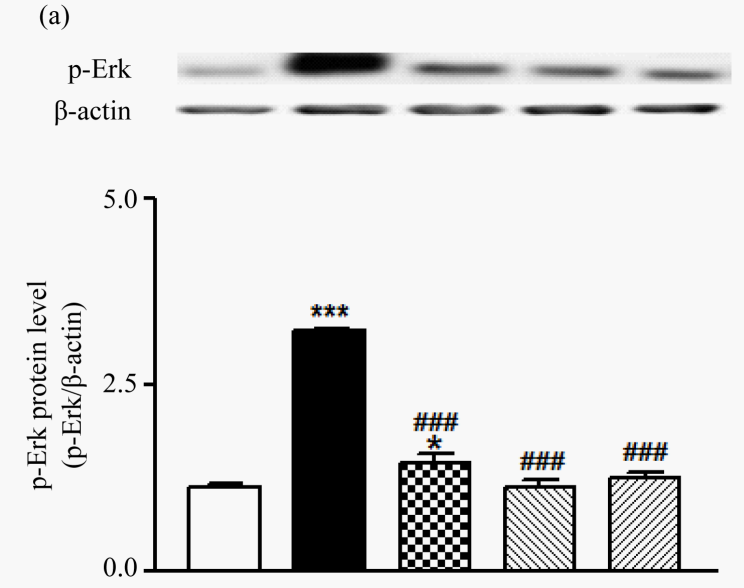

(b)

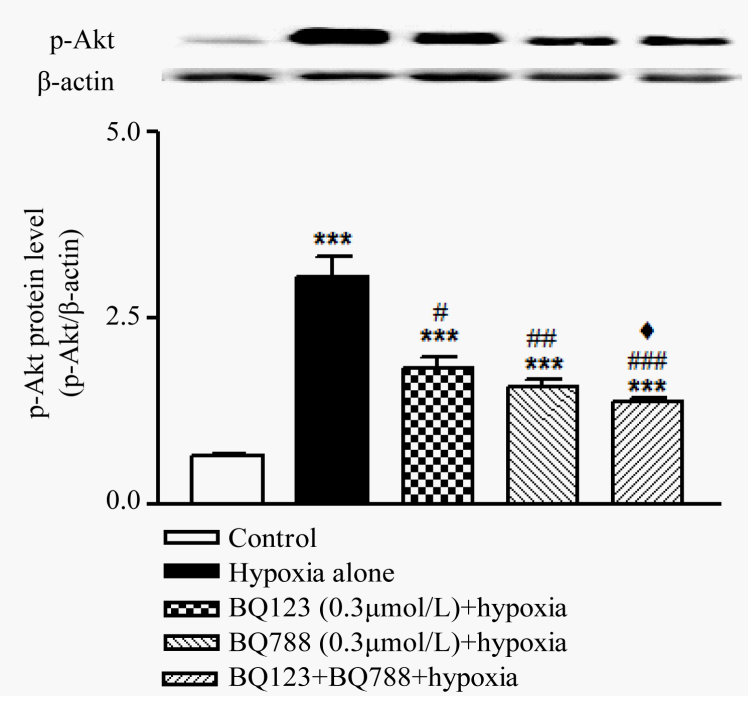

Figure 4. Effects of BQ123 $(0.3 \mu \mathrm{mol} / \mathrm{L})$ and BQ788 $(0.3 \mu \mathrm{mol} / \mathrm{L})$ on the regulation of hypoxia-induced expression of atrial phosphorylated (p)-ERK, (a) and p-Akt (b). Data are expressed as the mean \pm SE $(\mathrm{n}=5)$. ${ }^{*} \mathrm{P}<0.05,{ }^{* * *} \mathrm{P}<0.001$ vs. control; ${ }^{\#} \mathrm{P}<0.05,{ }^{\# \#} \mathrm{P}<0.01$,

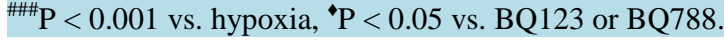

\subsection{Effect of ETRs on Hypoxia-Induced ANP Secretion}

We then used ETR antagonists to determine if ET-1-mediated stimulation of ETRs is involved in the regulation of hypoxia-induced secretion of ANP. BQ123 $\left(0.3 \mu \mathrm{mol} / \mathrm{L}\right.$; for ETR $\left.\mathrm{E}_{\mathrm{A}}\right)$ and BQ788 $\left(0.3 \mu \mathrm{mol} / \mathrm{L}\right.$; for ETR $\left.\mathrm{B}_{\mathrm{B}}\right)$ significantly $(\mathrm{P}<0.001$ vs. hypoxia, $\mathrm{n}=6$ ) attenuated hypoxia-mediated secretion of ANP (Figure 2(Ab) and Figure 2(Bb)). The inhibitory effect was markedly ( $P<0.001$ vs. hypoxia; $n=6$ ) enhanced with the co-treatment of both antagonists (Figure 2(Cb)). These results indicated that endogenous ET-1-mediated stimulation of ETRs was involved in the regulation of hypoxia-induced secretion of ANP.

\subsection{Effects of the ERK and Akt Signaling Pathways on Regulation of Hypoxia-Induced Secretion of ANP}

The MAPK/ERK and PI3K/Akt signaling pathways are considered important players in the effects mediated by ET-1 [16]-[18]. Therefore, we investigated the effects of ERK and Akt on hypoxia-induced secretion of ANP. The data showed that both inhibitors of ERK and Akt, PD98059 (30.0 $\mu \mathrm{mol} / \mathrm{L})$ and LY294002 $(30.0 \mu \mathrm{mol} / \mathrm{L})$, 
significantly attenuated hypoxia-induced secretion of ANP ( $P<0.001$ vs. hypoxia; $n=6$. Figure $3(\mathrm{Ab})$ and Figure $3(\mathrm{Bb})$ ), and both inhibitors mimicked the effects of BQ123 and BQ788 on the regulation of hypoxiainduced ANP secretion. These results indicated that the MAPK/ERK and PI3K/Akt signaling pathways may have been involved in endogenous ET-1-mediated regulation of hypoxia-induced ANP secretion.

\subsection{Effect of Endogenous ET-1 on the Expression of Hypoxia-Induced Atrial ERK and Akt}

To confirm that ERK and Akt were involved in ET-1-mediated regulation of hypoxia-induced ANP secretion, we investigated the effects of the ETR antagonists on the expression of p-ERK and p-Akt. Acute hypoxia markedly ( $\mathrm{P}<0.001$ vs. control; $\mathrm{n}=5$ ) increased atrial p-ERK levels (Figure 4(a)), and this effect was completely abolished ( $<0.001$ vs. hypoxia; $n=5$ ) by BQ788 or BQ123 plus BQ788 (Figure 4(a)). BQ123 also significantly ( $P<0.001$ vs. hypoxia; $n=5$ ) attenuated the hypoxia-induced increase in atrial p-ERK levels (Figure 4(a)).

p-Akt levels were markedly ( $\mathrm{P}<0.001$ vs. control; $\mathrm{n}=5$ ) increased by hypoxia (Figure 4(b)), and this effect was significantly attenuated by BQ123 ( $<0.05$ vs. hypoxia; $n=5)$ or BQ788 $(\mathrm{P}<0.01$ vs. hypoxia; $\mathrm{n}=5$ ), or both antagonists together $(P<0.001$ vs. hypoxia; $n=5)$. These results suggested that ET-1 regulated hypoxiainduced atrial ANP secretion through the activation of the MAPK/ERK and PI3K/Akt signaling pathways.

\section{Discussion}

The present study showed that acute hypoxia significantly promoted the release of atrial ET-1 and upregulated the expression of $\mathrm{ETR}_{\mathrm{A}}$ and $\mathrm{ETR}_{\mathrm{B}}$. We also demonstrated that hypoxia-mediated production of ET-1 caused the activation of ETRs resulting in the regulation of ANP secretion via the MAPK/ERK and -PI3K/Akt signaling pathways.

Previous studies have demonstrated that hypoxia is the predominant stimulus for the production of ET-1 in endothelial cells and the primary cause for the increased synthesis and release of ET-1 during myocardial ischemia [19]-[22]. Increased ET-1 secretion during myocardial ischemia has been linked to enhanced contractility in the failing heart [23] and to heart failure [24]. Recently, the hypoxia-inducible factor-1 $\alpha$ (HIF-1 $\alpha$ ) binding site in the pre-ET- 1 gene in cardiomyocytes has been identified as a site of synthesis and action for ET-1 in hypoxia-induced expression of ET-1 [25]-[27]. These findings were also reported in the present study, in which acute hypoxia significantly increased atrial ET-1 release in the isolated perfused beating rabbit atria. Furthermore, our findings revealed that acute hypoxia markedly up regulated the expression of $\mathrm{ETR}_{\mathrm{A}}$ and $\mathrm{ETR}_{\mathrm{B}}$ and potently stimulated the secretion of ANP, which was significantly attenuated by the $\mathrm{ETR}_{\mathrm{A}}$ or $\mathrm{ETR}_{\mathrm{B}}$ antagonist, BQ123 or ETR $\mathrm{B}_{\mathrm{B}}$ BQ788, respectively. These results indicated that acute hypoxia-mediated endogenous ET-1 contributed to the hypoxia-induced secretion of ANP through the activation of $\mathrm{ETR}_{\mathrm{A}}$ and $\mathrm{ETR}_{\mathrm{B}}$. In our previous study, both $\mathrm{ETR}_{\mathrm{A}}$ and $\mathrm{ETR}_{\mathrm{B}}$ were found to be involved in the regulation of ET-1-mediated ANP secretion in isolated perfused beating rabbit normoxic atria [11]. Therefore, these findings suggest that both ETRs play an important role in the regulation of ET-1-mediated ANP secretion in either normoxic or hypoxic conditions. Moreover, Zhang et al. [13] have reported that the nonselective ETR antagonist bosentan, and not BQ123, significantly attenuates hypoxia-induced secretion of ANP. However, Skvorak et al. [14] have shown that anoxiaincreased secretion of ANP is almost entirely blocked by BQ123 in isolated perfused rat atria. These discrepancies may be attributed to species or model differences, or different levels of endogenous ET-1.

Accumulating evidence has suggested that MAPK/ERK and PI3K/Akt are the most important downstream signaling pathways of ETRs [16]-[18]. Furthermore, findings from our previous study have revealed that the MAPK/ERK and PI3K/Akt signaling pathways are the most important regulators of ANP secretion in normoxic or hypoxic conditions [11]. However, whether or not these two pathways are involved in the regulation of endogenous ET-1 on hypoxia-induced atrial ANP secretion is unclear. Therefore, in the present study, we investigated the effect of endogenous ET-1 on the hypoxia-induced expression of p-ERK and p-Akt in isolated rabbit atria. The results showed that both ETR antagonists significantly down regulated the hypoxia-mediated increased expression of both phosphorylated proteins, concomitantly with a marked attenuation in the secretion of ANP. The regulation of hypoxia-induced ANP secretion by the p-ERK and Akt antagonists (PD98059 and LY294002, respectively) was mimicked by the ETR antagonists. These findings corroborate with previous results suggesting that the MAPK/ERK and PI3K/Akt signaling pathways contributed to the regulation of endogenous ET-1 on hypoxia-induced ANP secretion [11]. 


\section{Conclusion}

In conclusion, our findings indicate that acute hypoxia significantly promotes the production of atrial ET-1 which, in turn, regulates ANP secretion through the activation of ETR and the subsequent MAPK/ERK and -PI3K/Akt signaling pathways. These two pathways may be the mechanisms responsible for atrial endocrine effects under hypoxic conditions.

\section{Acknowledgements}

This work was supported by the National Natural Science Foundation of China (No. 81360061 and 81260035) and Jilin Provincial Research Foundation for Basic Research, China (No. 20130101133JC).

\section{References}

[1] Dobrucki, L.W., Meoli, D.F., Hu, J., Sadeghi, M.M. and Sinusas, A.J. (2009) Regional Hypoxia Correlates with the Uptake of a Radiolabeled Targeted Marker of Angiogenesis in Rat Model of Myocardial Hypertrophy and Ischemic Injury. Journal of Physiology and Pharmacology, 60, 117-123.

[2] Kim, D.K., Choi, E., Song, B.W., Cha, M.J., Ham, O., Lee, S.Y., Lee, C.Y., Park, J.H., Song, H. and Wang, K.C. (2012) Differentially Regulated Functional Gene Clusters Identified in Early Hypoxic Cardiomyocytes. Molecular Biology Reports, 39, 9549-9556. http://dx.doi.org/10.1007/s11033-012-1819-1

[3] Hong, L., Xi, J., Zhang, Y., Tian, W., Xu, J., Cui, X. and Xu, Z. (2012) Atrial Natriuretic Peptide Prevents the Mitochondrial Permeability Transition Pore Opening by Inactivating Glycogen Synthase Kinase 3beta via PKG and PI3K in Cardiac H9c2 Cells. European Journal of Pharmacology, 695, 13-19. http://dx.doi.org/10.1016/j.ejphar.2012.07.053

[4] Arjamaa, O. and Nikinmaa, M. (2011) Hypoxia Regulates the Natriuretic Peptide System. International Journal of Physiology, Pathophysiology and Pharmacology, 3, 191-201.

[5] Chen, Y.F. (2005) Atrial Natriuretic Peptide in Hypoxia. Peptides, 26, 1068-1077. http://dx.doi.org/10.1016/j.peptides.2004.08.030

[6] Plumpton, C., Ferro, C.J., Haynes, W.G., Webb, D.J. and Davenport, A.P. (1996) The Increase in Human Plasma Immunoreactive Endothelin but Not Big Endothelin-1 or Its C-Terminal Fragment Induced by Systemic Administration of the Endothelin Antagonist TAK-044. British Journal of Pharmacology, 119, 311-314. http://dx.doi.org/10.1111/j.1476-5381.1996.tb15987.x

[7] Iwanaga, Y., Kihara, Y., Hasegawa, K., Inagaki, K., Yoneda, T., Kaburagi, S., Araki, M. and Sasayama, S. (1998) Cardiac Endothelin-1 Plays a Critical Role in the Functional Deterioration of Left Ventricles during the Transition from Compensatory Hypertrophy to Congestive Heart Failure in Salt-Sensitive Hypertensive Rats. Circulation, 98, 2065-2073. http://dx.doi.org/10.1161/01.CIR.98.19.2065

[8] Wei, C.M., Lerman, A., Rodeheffer, R.J., McGregor, C.G., Brandt, R.R., Wright, S., Heublein, D.M., Kao, P.C., Edwards, W.D. and Burnett, J.C. (1994) Endothelin in Human Congestive Heart Failure. Circulation, 89, 1580-1586. http://dx.doi.org/10.1161/01.CIR.89.4.1580

[9] Sakai, S., Miyauchi, T., Kobayashi, M., Yamaguchi, I., Goto, K. and Sugishita, Y. (1996) Inhibition of Myocardial Endothelin Pathway Improves Long-Term Survival in Heart Failure. Nature, 384, 353-355. http://dx.doi.org/10.1038/384353a0

[10] Dietz, J.R. (2005) Mechanisms of Atrial Natriuretic Peptide Secretion from the Atrium. Cardiovascular Research, 68, 8-17. http://dx.doi.org/10.1016/j.cardiores.2005.06.008

[11] Liu, L.P., Hong, L., Yu, L., Li, H.Y., Ding, D.Z., Jin, S.J. and Cui, X. (2012) Ouabain Stimulates Atrial Natriuretic Peptide Secretion via the Endothelin-1/ETB Receptor-Mediated Pathway in Beating Rabbit Atria. Life Sciences, 90, 793-798. http://dx.doi.org/10.1016/j.lfs.2012.04.008

[12] Belaidi, E., Joyeux-Faure, M., Ribuot, C., Launois, S.H., Levy, P. and Godin-Ribuot, D. (2009) Major Role for Hypoxia Inducible Factor-1 and the Endothelin System in Promoting Myocardial Infarction and Hypertension in an Animal Model of Obstructive Sleep Apnea. Journal of the American College of Cardiology, 53, 1309-1317. http://dx.doi.org/10.1016/j.jacc.2008.12.050

[13] Zhang, Y., Oliver, J.R. and Horowitz, J.D. (2004) The Role of Endothelin in Mediating Ischemia/Hypoxia-Induced Atrial Natriuretic Peptide Release. Journal of Cardiovascular Pharmacology, 43, 227-233. http://dx.doi.org/10.1097/00005344-200402000-00010

[14] Skvorak, J.P., Nazian, S.J. and Dietz, J.R. (1995) Endothelin Acts as a Paracrine Regulator of Stretch-Induced Atrial Natriuretic Peptide Release. The American Journal of Physiology, 269, R1093-R1098.

[15] Zhang, Q.L., Cui, B.R., Li, H.Y., Li, P., Hong, L., Liu, L.P., Ding, D.Z. and Cui, X. (2013) MAPK and PI3K Pathways 
Regulate Hypoxia-Induced Atrial Natriuretic Peptide Secretion by Controlling HIF-1 Alpha Expression in Beating Rabbit Atria. Biochemical and Biophysical Research Communications, 438, 507-512. http://dx.doi.org/10.1016/j.bbrc.2013.07.106

[16] Sugden, P.H. (2003) An Overview of Endothelin Signaling in the Cardiac Myocyte. Journal of Molecular Cellular Cardioliology, 35, 871-886. http://dx.doi.org/10.1016/S0022-2828(03)00153-6

[17] Schorlemmer, A., Matter, M.L. and Shohet, R.V. (2008) Cardioprotective Signaling by Endothelin. Trends in Cardiovascular Medicine, 18, 233-239. http://dx.doi.org/10.1016/j.tcm.2008.11.005

[18] Pham, F. and Cole, S. (2001) A Clerk: Regulation of Cardiac Myocyte Protein Synthesis through Phosphatidylinositol 3' Kinase and Protein Kinase B. Advances in Enzyme Regulation, 41, 73-86. http://dx.doi.org/10.1016/S0065-2571(00)00007-8

[19] Watanabe, T., Suzuki, N., Shimamoto, N., Fujino, M. and Imada, A. (1990) Endothelin in Myocardial Infarction. Nature, 334, 114. http://dx.doi.org/10.1038/344114a0

[20] Winkles, J.A., Alberts, G.F., Brogi, E. and Libby, P. (1993) Endothelin-1 and Endothelin Receptor mRNA Expression in Normal and Atherosclerotic Human Arteries. Biochemical and Biophysical Research Communications, 191, 10811088. http://dx.doi.org/10.1006/bbrc.1993.1327

[21] Tsuji, S., Sawamura, A., Watanabe, H., Taihara, K., Park, S.E. and Azuma, J. (1991) Plasma Endothelin Levels during Myocardial Ischemia and Reperfusio. Life Sciences, 48, 1745-1749. http://dx.doi.org/10.1016/0024-3205(91)90211-S

[22] Tonnessen, T., Giaid, A., Naess, P.A., Yanigasawa, M. and Christensen, G. (1994) Increased in Vivo Expression and Production of Endothelin-1 by Porcine Cardiomyocytes Subjected to Ischemia. Circulation, 90, 426.

[23] Sakai, S., Miyauchi, T., Sakurai, T., Kasuya, Y., Ihara, M., Yamaguchi, I., Goto, K. and Sugishita, Y. (1996) Endogenous Endothelin-1 Participates in the Maintenance of Cardiac Function in Rats with Congestive Heart Failure. Marked increase in Endothelin-1 Production in the Failing Heart. Circulation, 93, 1214-1222. http://dx.doi.org/10.1161/01.CIR.93.6.1214

[24] Sakai, S., Miyauchi, T., Kobayashi, M., Yamaguchi, I., Goto, K. and Sugishita, Y. (1996) Inhibition of Myocardial Endothelin Pathway Improves Long-Term Survival in Heart Failure. Nature, 384, 353-355. http://dx.doi.org/10.1038/384353a0

[25] Kedzierski, R.M. and Yanagisawa, M. (2001) Endothelin System: The Double-Edged Sword in Health and Disease. Annual Review of Pharmacology and Toxicology, 41, 851-876. http://dx.doi.org/10.1146/annurev.pharmtox.41.1.851

[26] Hu, J., Discher, D.J., Bishopric, N.H. and Webster, K.A. (1998) Hypoxia Regulates Expression of the Endothelin-1 Gene through a Proximal Hypoxia-Inducible Factor-1 Binding Site on the Antisense Strand. Biochemical and Biophysical Research Communications, 245, 894-898. http://dx.doi.org/10.1006/bbrc.1998.8543

[27] Kohan, D.E., Rossi, N.F., Inscho, E.W. and Pollock, D.M. (2011) Regulation of Blood Pressure and Salt Homeostasis by Endothelin. Physiological Reviews, 91, 1-77. http://dx.doi.org/10.1152/physrev.00060.2009 